\title{
What Are the Real-World Podcast-Listening Habits of Medical Professionals?
}

Damian Roland ${ }^{1}$, Brent Thoma ${ }^{2}$, Andrew Tagg ${ }^{3}$, Jason Woods ${ }^{4}$, Teresa M. Chan ${ }^{5}$, Jeffrey Riddell ${ }^{6}$

1. Children's Emergency Medicine, Leicester University and Hospitals, Leicester, GBR 2. Emergency Medicine, University of Saskatchewan, Saskatoon, CAN 3. Emergency Medicine, Footscray Hospital, University of Melbourne, Melbourne, AUS 4. Emergency Medicine, University of Colorado School of Medicine, Aurora, USA 5. Emergency Medicine, McMaster University, Hamilton, CAN 6. Emergency Medicine, University of Southern California Keck School of Medicine, Los Angeles, USA

Corresponding author: Jeffrey Riddell, jeffriddell@gmail.com

\section{Abstract}

\section{Introduction}

Educational podcasts are increasingly being utilized by health professionals for continuing education, but how they are being used remains poorly understood. Given their extensive reach, they represent a phenomenal opportunity for researchers to engage in knowledge translation of their scholarly works. The design, study, and effectiveness of these resources should be informed by a deeper understanding of their pragmatic usage. We aimed to prospectively determine the pragmatic, real-world listening habits of health professionals.

\section{Methods}

We performed a prospective observational study of a broad, interprofessional sample of participants (medical students, residents, physicians, nurses, physician assistants, and paramedics) recruited through a multimodal social media (Twitter and Facebook) campaign. Recruitment materials included an infographic and study website. Participants listened to eight podcasts and described their use of each in subsequent questionnaires.

\section{Results}

A total of 393 participants enrolled in the study, and 241 completed the survey for all eight podcasts. Listening behaviors were consistent across the podcasts with the majority selecting a normal speed of playback and engaging in concomitant activities such as driving. One-third of participants paused the podcasts due to interruption.

\section{Conclusion}

Review began 06/09/2021 Review ended 06/18/2021 Published 07/07/2021

\section{(c) Copyright 2021}

Roland et al. This is an open access article distributed under the terms of the Creative Commons Attribution License CC-BY 4.0., which permits unrestricted use, distribution, and reproduction in any medium, provided the original author and source are credited.
We describe the prospective use of medical podcasts by a cohort of health professionals. This work should inform the role of podcasts in the communication of medical research.

Categories: Emergency Medicine, Medical Education, Healthcare Technology Keywords: podcasts, medical education, listening habits, playback speed, multitasking

\section{Introduction}

There is increasing evidence that methods for engaging in knowledge translation and, hence, education of frontline health professionals are changing [1]. Podcasts are playing an increasing role in the postpublication discussion of medical research and as a source of asynchronous learning for clinicians, who use them to both facilitate and supplement learning [2-4]. However, relatively little is known about how they are being used. Previous literature has found that many clinicians report listening while conducting other tasks [5]. This "multitasking" may result in only partial attention to the podcast, suggesting that clinicians' listening habits may not be fully aligned with their stated goals of learning [6,7]. The disconnect between reported listening habits and optimal learning behaviors may be significant, given the reported impact of podcasts on clinical decisions, and may decrease their potential as knowledge translation vehicles [4].

The literature on podcast-listening habits is largely retrospective and provides little granular detail to guide podcast utilization or further study [4,6,7]. Further, because podcasts are complexly interwoven [6] with individual learners and their habits; literature on other media may not translate to podcasts. We sought to provide a richer understanding of how listeners use podcast technology by investigating the pragmatic, realworld listening habits of health professionals.

\section{Materials And Methods}


We performed a prospective survey-based study of the listening habits of an interprofessional sample of emergency medicine and critical care clinicians. Study participants listened to eight emergency medicine and critical care podcasts and completed podcast-specific surveys after each. The study was deemed exempt from ethical review (Research Ethics Board at the University of Saskatchewan, BEH 17-170).

\section{Participant recruitment}

We recruited participants through the METRIQ (Medical Education Translational Resources: Impact and Quality) methodology as described in a previous publication [7]. Briefly, we shared information, predominately via Facebook and Twitter, about the study to a targeted virtual community of practice that utilizes Free Open Access Medical education resources such as podcasts [7]. We also reached out via email to our personal networks and collaborators from previous studies [8-10]. Interested participants submitted an intake form requesting further information and were considered formally enrolled after completing an initial survey containing a standard consent form [7]. To incentivize participation and acknowledge the extensive time commitment of this study, we recognized participants who completed all surveys as contributors.

\section{Survey design and podcast selection}

We selected podcasts listed on the Social Media Index [10-12] for inclusion in the study. Eight were selected because we felt that this was the maximum number that participants would be willing to complete. To increase the generalizability of our results, we ensured variety in podcaster accent and geographic origins (two each with native speakers from Canada, the United States, the United Kingdom, and Australia) as well as a number of podcasters (four with a single podcaster and four with multiple). In keeping with previous research about ideal podcast episode length [4], all selected podcasts were 17-23 minutes in length (Table 1). Preference was given to recently published podcasts to ensure relevance and decrease the likelihood of being previously heard by the participants. The owners of the eight podcasts provided consent for their use in the study. To encourage the participants to listen to the podcasts in their usual fashion, a dedicated podcast channel was created via Soundcloud.com that could be added to any podcast application or accessed via any web browser.

\begin{tabular}{|c|c|c|c|}
\hline Podcast & Country of origin & Number of speakers & Length (minutes) \\
\hline Broomedocs & Australia & Multiple & 23 \\
\hline Royal College of Emergency Medicine (United Kingdom) & United Kingdom & Single & 23 \\
\hline CRACKCast & Canada & Multiple & 22 \\
\hline EMCrit & United States & Single & 23 \\
\hline FOAMcast & United States & Multiple & 23 \\
\hline PHARM Podcast & Australia & Single & 21 \\
\hline Skeptic's Guide to Emergency Medicine & Canada & Single & 17 \\
\hline Resus Room & United Kingdom & Multiple & 21 \\
\hline
\end{tabular}

TABLE 1: Characteristics of the selected podcasts

Each podcast-specific survey questionnaire investigated the real-world habits of the participants. Questions explored when the listening occurred, at what speed, whether simultaneous activities were performed, whether notes were taken, if (and why) the podcast was paused, if (and why) segments were repeated, whether an accent affected listening, and the audio quality. These were based on known effective learning techniques [13], previous podcast research [5-7], and the real-world experiences of the authors.

\section{Protocol}

Participants were directed to a dedicated podcast channel and asked to listen to a podcast and respond to a brief questionnaire after listening (Appendix A). Participants were instructed to complete each of the eight podcast surveys immediately after listening to their respective podcasts. They could choose any order in which to listen to the eight podcasts. Participants then received reminder emails for each follow-up survey every one to two weeks up to a maximum of four times.

\section{Analysis}

Raw survey data was exported from FluidSurveys in a spreadsheet format, and descriptive statistics were calculated using Microsoft Excel (Microsoft Corp., Redmond, WA, USA). 


\section{Cureus}

\section{Results}

Recruitment occurred between September 10, 2017, and December 9, 2017. The study surveys were accessible until March 8, 2018 (a minimum of three months). A total of 390 healthcare professionals formally enrolled in the study, and 241 completed all eight podcast surveys (61.8\% study completion rate). Table 2 contrasts the demographics of the participant group that enrolled in the study and the group that completed all surveys. The groups' demographics were grossly similar.

\begin{tabular}{|c|c|c|c|}
\hline & Variable & $\begin{array}{l}\text { Enrolled in the study, } \mathrm{n} \\
(\%)\end{array}$ & Completed the study, $\mathrm{n}(\%)$ \\
\hline \multirow{6}{*}{ Age } & $18-24$ & $41(10.5)$ & $23(9.5)$ \\
\hline & $25-34$ & $204(52.3)$ & $133(55.2)$ \\
\hline & $35-44$ & $111(28.5)$ & $65(27.0)$ \\
\hline & $45-54$ & $25(6.4)$ & $16(6.6)$ \\
\hline & $55-65$ & $9(2.3)$ & $4(1.6)$ \\
\hline & $>65$ & $0(0 \%)$ & 0 \\
\hline \multirow{3}{*}{ Gender } & Female & $175(44.5)$ & 105 (43.6) \\
\hline & Male & $215(54.7)$ & $135(56.0)$ \\
\hline & Decline to state/other & $3(0.8)$ & $1(0.4)$ \\
\hline \multirow{7}{*}{ Modality of recruitment } & Twitter & $144(36.9)$ & 78 (32.4) \\
\hline & Email or in-person by a study author & $99(25.4)$ & $73(30.3)$ \\
\hline & Facebook & $69(17.7)$ & 47 (19.5) \\
\hline & METRIQ Blog Study participant & $59(15.1)$ & 44 (18.3) \\
\hline & Peer referral & $35(9.0)$ & $18(7.5)$ \\
\hline & Medical website or podcast & $19(4.9)$ & $12(5.0)$ \\
\hline & WhatsApp & $15(3.8)$ & $6(2.5)$ \\
\hline \multirow{7}{*}{ Background/level of training } & Practicing Physician, Attending, Consultant & $111(27.7)$ & $73(30.2)$ \\
\hline & Resident, House Officer, or Graduate Trainee & 79 (19.7) & $40(16.5)$ \\
\hline & Medical Student & $81(20.2)$ & $66(27.3)$ \\
\hline & Nurse, Physician Assistant, or Paramedic & $121(30.2)$ & $58(24.0)$ \\
\hline & Nurse, Physician Assistant, or Paramedic Student & $4(1.0)$ & $3(1.2)$ \\
\hline & $>1$ category & $3(0.7)$ & $2(0.8)$ \\
\hline & Other (Infection Control Practitioner) & $2(0.5)$ & $0(0)$ \\
\hline \multirow{10}{*}{ Home country } & Canada & $150(38.5)$ & $122(50.6)$ \\
\hline & United States & $118(30.3)$ & $59(24.5)$ \\
\hline & Europe & 67 (17.2) & 32 (13.3) \\
\hline & Australia/New Zealand & $23(5.9)$ & $14(5.8)$ \\
\hline & Africa & $19(4.9)$ & $9(3.7)$ \\
\hline & South America & $7(1.8)$ & $4(1.7)$ \\
\hline & Asia & $6(1.5)$ & $1(0.4)$ \\
\hline & To review new literature & $298(75.8)$ & $181(75.1)$ \\
\hline & To learn core material & $295(75.1)$ & $190(78.8)$ \\
\hline & To refresh memory & $282(71.8)$ & $185(76.8)$ \\
\hline
\end{tabular}




\section{Cureus}

\begin{tabular}{|c|c|c|c|}
\hline \multirow{6}{*}{ Reason for listening to podcasts } & Inspiration & $179(45.5)$ & 109 (45.2) \\
\hline & Entertainment & $160(40.7)$ & 105 (43.6) \\
\hline & To feel connected to the community & $143(36.4)$ & $88(36.5)$ \\
\hline & To keep up with the medical terminology & $103(26.2)$ & $57(23.7)$ \\
\hline & For board certification/re-certification review & $63(16.0)$ & $29(12.0)$ \\
\hline & Other & $28(7.1)$ & $19(7.9)$ \\
\hline \multirow{4}{*}{ Podcast involvement } & Podcast manager, operator, or owner & $38(9.7)$ & $20(8.3)$ \\
\hline & Not a podcast manager, operator, or owner & $352(90.3)$ & 221 (91.7) \\
\hline & Daily & $28(7.2)$ & $34(14.1)$ \\
\hline & Weekly & $178(45.6)$ & 120 (49.8) \\
\hline \multirow[t]{3}{*}{ Podcast-listening frequency } & Monthly & $102(26.2)$ & $61(25.3)$ \\
\hline & Yearly & $27(6.9)$ & $16(6.6)$ \\
\hline & Never & $28(7.2)$ & $10(4.1)$ \\
\hline
\end{tabular}

TABLE 2: Demographics of the METRIQ podcast study participants who enrolled in and completed the study

METRIQ, Medical Education Translational Resources: Impact and Quality.

The participants' listening habits were relatively consistent across the podcasts (Table 3). The average listening speed varied minimally across podcasts from 1.11 to 1.16 . Most listened at normal (1x) speed (range: $73.4 \%-81.9 \%$ ), and only a minority listened at $\geqslant 1.5 x$ speed (range: $13.9 \%-21.3 \%$ ).

\begin{tabular}{|l|l|l|l|l|l|l|l|l|}
\hline & Podcast 1 & Podcast 2 & Podcast 3 & Podcast 4 & Podcast 5 & Podcast 6 & Podcast 7 & Podcast 8 \\
\hline Number at 0.5-0.99x (\%) & $1(0.3)$ & $1(0.4)$ & $2(0.8)$ & $1(0.4)$ & $2(0.8)$ & $0(0.0)$ & $0(0.0)$ & $1(0.4)$ \\
\hline Number at 1x (\%) & $253(81.9)$ & $223(78.2)$ & $210(79.8)$ & $200(78.1)$ & $192(76.8)$ & $179(73.4)$ & $191(78.9)$ & $184(76.3)$ \\
\hline Number at 1.01-1.49x (\%) & $12(3.9)$ & $17(6.0)$ & $12(4.6)$ & $12(4.7)$ & $14(5.6)$ & $13(5.3)$ & $12(5.0)$ & $14(5.8)$ \\
Number at 1.5-1.99x (\%) & $31(10.0)$ & $30(10.5)$ & $29(11.0)$ & $34(13.3)$ & $32(12.8)$ & $40(16.4)$ & $32(13.2)$ & $31(12.9)$ \\
Number at >2.00x (\%) & $12(3.9)$ & $14(4.9)$ & $10(3.8)$ & $9(3.5)$ & $10(4.0)$ & $12(4.9)$ & $7(2.9)$ & $11(4.6)$ \\
Total & 309 & 285 & 263 & 256 & 250 & 244 & 242 & 241 \\
\hline
\end{tabular}

TABLE 3: Number (percentage) of participants listening to podcasts at each of the podcasts at a range of speeds

Approximately one-quarter of participants (range 19.6\%-28.5\%) did not participate in concomitant activities while listening. When concomitant activities were performed, driving (25.9\%-31.6\%), chores (16.9\%-22.5\%), and exercise (9.1\%-12.4\%) were the most common (Table 4). 


\section{Cureus}

\begin{tabular}{|l|l|l|l|l|l|l|l|l|}
\hline Activity performed & Podcast 1 & Podcast 2 & Podcast 3 & Podcast 4 & Podcast 5 & Podcast 6 & Podcast 7 & Podcast 8 \\
\hline None & $62(20.1)$ & $56(19.6)$ & $66(25.1)$ & $49(19.1)$ & $49(19.6)$ & $63(25.8)$ & $69(28.5)$ & $63(26.1)$ \\
Chores & $68(22.0)$ & $64(22.5)$ & $50(19.0)$ & $55(21.5)$ & $52(20.8)$ & $42(17.2)$ & $41(16.9)$ & $44(18.3)$ \\
Exercise & $28(9.1)$ & $32(11.2)$ & $30(11.4)$ & $30(11.7)$ & $26(10.4)$ & $28(11.5)$ & $30(12.4)$ & $26(10.8)$ \\
Driving & $80(25.9)$ & $83(29.1)$ & $82(31.2)$ & $86(33.6)$ & $76(30.4)$ & $77(31.6)$ & $70(28.9)$ & $71(29.5)$ \\
Other & $81(26.2)$ & $68(23.9)$ & $54(20.5)$ & $50(19.5)$ & $58(23.2)$ & $47(19.3)$ & $39(16.1)$ & $47(19.5)$ \\
Total & 319 & 303 & 282 & 270 & 261 & 257 & 249 & 251 \\
\hline
\end{tabular}

TABLE 4: Number (percentage) of participants performing concomitant activities while listening to each of the podcasts

Only a small fraction of participants took notes (0.8\%-6.1\%), but approximately one-third paused the podcast (19.4\%-36.6\%) with the most common reason being an interruption (13.6\%-27.4\%) (Table 5). The proportion of listeners that repeated $(9.7 \%-49.3 \%)$ a segment of the podcast was quite variable. When portions were repeated, it was most often because the listener felt that they had missed important information (55.0\%-68.8\%).

\begin{tabular}{|c|c|c|c|c|c|c|c|c|}
\hline Reason cited & $\begin{array}{l}\text { Podcast } \\
1\end{array}$ & $\begin{array}{l}\text { Podcast } \\
2\end{array}$ & $\begin{array}{l}\text { Podcast } \\
3\end{array}$ & $\begin{array}{l}\text { Podcast } \\
4\end{array}$ & $\begin{array}{l}\text { Podcast } \\
5\end{array}$ & $\begin{array}{l}\text { Podcast } \\
6\end{array}$ & $\begin{array}{l}\text { Podcast } \\
7\end{array}$ & $\begin{array}{l}\text { Podcast } \\
8\end{array}$ \\
\hline \multicolumn{9}{|l|}{ Pausing } \\
\hline $\begin{array}{l}\text { To stop the flow of new content to allow me to process } \\
\text { information }\end{array}$ & $18(13.3)$ & $19(15.8)$ & $34(25.0)$ & $19(22.9)$ & $10(11.9)$ & $3(4.8)$ & $7(13.2)$ & $7(11.9)$ \\
\hline $\begin{array}{l}\text { To facilitate memorization of information before moving } \\
\text { on }\end{array}$ & $5(3.7)$ & $7(5.8)$ & $20(14.7)$ & $5(6.0)$ & $6(7.1)$ & $3(4.8)$ & $4(7.5)$ & $7(11.9)$ \\
\hline To break up the podcast into more digestible segments & $9(6.7)$ & $9(7.5)$ & $16(11.8)$ & $3(3.6)$ & $6(7.1)$ & $6(9.7)$ & $4(7.5)$ & $5(8.5)$ \\
\hline $\begin{array}{l}\text { I wasn't able to listen to the entire podcast at once due to } \\
\text { interruptions }\end{array}$ & $80(59.3)$ & $78(65.0)$ & $58(42.6)$ & $51(61.4)$ & $56(66.6)$ & $41(66.1)$ & $33(62.3)$ & $35(22.0)$ \\
\hline Other & $23(17.0)$ & $7(5.8)$ & $8(5.9)$ & $6(7.2)$ & $6(7.1)$ & $9(14.5)$ & $5(9.4)$ & $5(8.5)$ \\
\hline Total & 135 & 120 & 136 & 83 & 84 & 62 & 53 & 59 \\
\hline \multicolumn{9}{|l|}{ Repeating } \\
\hline To reinforce information & $10(14.5)$ & $18(22.8)$ & $37(30.3)$ & $16(27.6)$ & $15(24.6)$ & $3(8.3)$ & $4(11.7)$ & $15(21.4)$ \\
\hline To ensure that I haven't missed important information & $23(33.3)$ & $23(29.1)$ & $34(27.9)$ & $17(29.3)$ & $16(26.2)$ & $12(33.3)$ & $9(26.5)$ & $20(28.6)$ \\
\hline Because I know I have missed important information & 32 (46.4) & $34(43.0)$ & $43(35.3)$ & $22(37.9)$ & $27(44.3)$ & $16(44.4)$ & $17(50.0)$ & $33(47.1)$ \\
\hline Other & $4(5.8)$ & $4(5.1)$ & $8(6.6)$ & $3(5.2)$ & $3(4.9)$ & $5(13.9)$ & $4(11.7)$ & $2(2.9)$ \\
\hline Total & 69 & 79 & 122 & 58 & 61 & 36 & 34 & 70 \\
\hline
\end{tabular}

TABLE 5: Rationale and number (percentage) of participants pausing or repeating segments while listening to each of the podcasts

\section{Discussion}

Scholars interested in the knowledge translation of new findings in the health sciences must consider the limitations of this modality to maximize effective education for end-users. In this exploration of the podcast-listening behaviors of an interprofessional cohort of health professionals, most participants played podcasts at normal speed and participated in another activity (usually driving) while they were listening. Listeners occasionally stopped the podcasts due to interruptions, while a minority repeated segments for 
Similar to previous studies, our participants reported performing simultaneous tasks (e.g., chores, exercise) while listening [5]. Our finding that approximately three-quarters of participants listen at $1 \mathrm{x}$ (normal) speed is in line with the self-reported behavior of emergency medicine (EM) residents and clinicians [6,7]. However, fewer of our participants drove relative to the high proportions described in self-report studies (up to $93 \%$ ) [6].

Our pragmatic approach gleaned several findings that could not be explored using self-report data. For example, the range of participants who paused and repeated sections of each podcast varied, suggesting that there may be differences between podcasts that make the listener more likely to be interrupted or want to review a segment (e.g., poor sound quality, complex content, speaker accent). A common reason cited for pausing or repeating sections was that information was missed. Podcast producers may consider using this information to modify their recordings to incorporate more repetition of key or complex information [14].

Our results reiterate the finding that clinicians are not listening to educational podcasts in ways that align with their most commonly cited reasons for listening: reviewing new literature, learning core material, and refreshing memory (Table 2). Multitasking and the lack of active learning behaviors (pausing, repeating, note-taking) are not in keeping with behaviors that foster a deep understanding of the material [13]. Multitasking in the form of listening and driving simultaneously may increase the listener's cognitive load, resulting in decreased driving performance and limited retention of podcast content [15]; however, a recent study found similar retention while driving and sitting in an undistracted setting [16]. The effect of exercise on cognitive performance is generally positive but varies with exercise duration, exercise intensity, and participant fitness [17]. Further, roughly $15 \%$ of participants listened at speeds $\geqslant 1.5 x$, a point at which there may be a significant drop-off in comprehension of speech [18]. If clinicians desire to listen - and podcasters desire to create podcasts - with a goal of deep learning and retention of the material, they may consider intentionally limiting distractions [19], pausing to enable connections between new material and existing knowledge, and repeating segments at spaced intervals [20]. Our study design did not allow the exploration of the impact of concurrent activities or listening strategies (e.g., variable listening speeds, interruptions, and repeating difficult segments) on knowledge acquisition but would support the further experimental study of these questions.

The strengths of our findings lie in our large and diverse study population and pragmatic approach. The enrolment of a large, diverse population of health professionals to listen to eight different podcasts and complete surveys on each allowed us to describe how podcast listeners utilize medical education podcasts in a real-world context. The results should inform research to determine how podcasts can be maximized for learning.

\section{Limitations}

While the number of participants in this study was high, our population was not necessarily representative of the wider body of health professionals. We note that roughly $25 \%$ of the cohort completing the study were students. Our goal was not to replicate this population but to recruit clinicians who listen to podcasts regularly as this sample is more relevant to our inquiry than a representative population including those who do not use podcasts. Still, most participants were from developed countries, and a quarter were students. We believe that the discrepancies between self-report and real-world listening habits demonstrate the value of our pragmatic methodology, although it is possible that our results were skewed by participants changing their listening habits to complete the study. Lastly, we lost a significant number of our target population during the study; this was not surprising, given that participation required listening to eight podcasts and completing eight surveys. The drop-off was consistent across the first four podcasts, with fewer participants dropping out on the final four. Fortunately, the demographics of the participants who enrolled in the study were similar to those who completed it, suggesting that this did not have a substantial impact on our results. Finally, a large number of participants did not list their location, restricting any further analysis of the role of the listeners' nationality in listening behavior.

\section{Conclusions}

Educational podcasts are increasingly being utilized by health professionals for continuing education, but how they are being used remains poorly understood. We performed a prospective survey-based study of the listening habits of an interprofessional sample of emergency medicine and critical care clinicians to determine the pragmatic, real-world listening habits of health professionals. Most health professionals who listened to medical education podcasts did so at normal playback speeds and engaged in other activities such as driving or exercise while listening. A minority of listeners paused or repeated segments. This work informs our understanding of the utilization of podcasts by end-users and may guide future research on optimizing podcast use for learning and knowledge translation.

\section{Appendices}

\section{Appendix A: Usage survey}




\section{Cureus}

Please respond to these questions in reference specifically to the [insert podcast name] podcast that you were assigned to this week.

1. When did you listen to the podcast?

Morning

Afternoon

Evening

Night

2. What device did you use to listen to the podcast?

Computer

Tablet

Smartphone: Apple

Smartphone: Android

Smartphone: Other

MP3 Player

Car Stereo

Other

3. What was your listening speed?

(e.g., $0.5 \mathrm{x}$ would mean that you slow the podcast down to $1 / 2$ speed, while $2.0 \mathrm{x}$ would mean that you double the speed of the podcast.)

4. Did you perform any simultaneous unrelated activities?

No

Chores

Exercise

Driving

Other

5. Did you take notes?

Yes

No

6. Did you ever pause the podcast?

Yes

No

7. If yes to the previous question, approximately how many times did you pause it? 


\section{Cureus}

\section{Did you ever repeat segments of the podcast?}

Yes

No

9. If yes to the previous question, how many times did you repeat segments of the podcast?

\section{Podcast critique}

1. Foreign accents

Did not impede the listening ability

Difficult but understandable

Indecipherable

N/A

2. Recording quality

High quality

Medium quality

Low quality

3. What was your prior knowledge of the content of the podcast?

None

Introductory

Intermediate

Advanced

\section{Short answer questions}

1. What was your key takeaway from the podcast?

2. Was the podcast well designed? Why or why not?

3. Was the content of high quality? Why or why not?

4. Was the podcast credible? Why or why not?

\section{Additional Information}

\section{Disclosures}

Human subjects: Consent was obtained or waived by all participants in this study. Research Ethics Board at the University of Saskatchewan issued approval BEH 17-170. The study was deemed exempt from ethical review. Animal subjects: All authors have confirmed that this study did not involve animal subjects or tissue. Conflicts of interest: In compliance with the ICMJE uniform disclosure form, all authors declare the following: Payment/services info: All authors have declared that no financial support was received from any organization for the submitted work. Financial relationships: All authors have declared that they have 
no financial relationships at present or within the previous three years with any organizations that might have an interest in the submitted work. Other relationships: All authors have declared that there are no other relationships or activities that could appear to have influenced the submitted work.

\section{Acknowledgements}

The authors would like to acknowledge Annet Alenyo Ngabirano, Katie Knight, Timothy Horeczko, Stevan Bruijns, and Scott Goerzen for their assistance in the recruitment of participants.

\section{References}

1. Chan TM, Dzara K, Dimeo SP, Bhalerao A, Maggio LA: Social media in knowledge translation and education for physicians and trainees: a scoping review. Perspect Med Educ. 2020, 9:20-30. 10.1007/s40037-01900542-7

2. Mallin M, Schlein S, Doctor S, Stroud S, Dawson M, Fix M: A survey of the current utilization of asynchronous education among emergency medicine residents in the United States. Acad Med. 2014, 89:598-601. 10.1097/ACM.0000000000000170

3. Purdy E, Thoma B, Bednarczyk J, Migneault D, Sherbino J: The use of free online educational resources by Canadian emergency medicine residents and program directors. CJEM. 2015, 17:101-6. 10.1017/cem.2014.73

4. Riddell J, Swaminathan A, Lee M, Mohamed A, Rogers R, Rezaie SR: A survey of emergency medicine residents' use of educational podcasts. West J Emerg Med. 2017, 18:229-34. 10.5811/westjem.2016.12.32850

5. Chin A, Helman A, Chan TM: Podcast use in undergraduate medical education . Cureus. 2017, 9:e1930. 10.7759/cureus.1930

6. Riddell J, Robins L, Brown A, Sherbino J, Lin M, Ilgen JS: Independent and interwoven: a qualitative exploration of residents' experiences with educational podcasts. Acad Med. 2020, 95:89-96. 10.1097/ACM.0000000000002984

7. Thoma B, Goerzen S, Horeczko T, et al.: An international, interprofessional investigation of the selfreported podcast listening habits of emergency clinicians: a METRIQ study. CJEM. 2020, 22:112-7. 10.1017/cem.2019.427

8. Thoma B, Sebok-Syer SS, Krishnan K, et al.: Individual gestalt is unreliable for the evaluation of quality in medical education blogs: a METRIQ study. Ann Emerg Med. 2017, 70:394-401. 10.1016/j.annemergmed.2016.12.025

9. Thoma B, Sebok-Syer SS, Colmers-Gray I, et al.: Quality evaluation scores are no more reliable than gestalt in evaluating the quality of emergency medicine blogs: a METRIQ study. Teach Learn Med. 2018, 30:294302. 10.1080/10401334.2017.1414609

10. Thoma B, Chan TM, Kapur P, et al.: The social media index as an indicator of quality for emergency medicine blogs: a METRIQ study. Ann Emerg Med. 2018, 72:696-702. 10.1016/j.annemergmed.2018.05.003

11. Social Media Index (SMi). (2016). Accessed: June 3, 2021: http://www.aliem.com/social-media-index/.

12. Thoma B, Sanders JL, Lin M, Paterson OS, Steeg J, Chan TM: The social media index: measuring the impact of emergency medicine and critical care websites. West J Emerg Med. 2015, 16:242-9. 10.5811/westjem.2015.1.24860

13. Bransford J, Division of Behavioral and Social Sciences and Education, National Academy of SciencesNational Research Council, Washington, DC., et al.: How People Learn: Brain, Mind, Experience, and School. National Academies Press, Washington, DC; 1999.

14. Riddell JC, Robins L, Sherbino J, Brown A, Ilgen J: Residents' perceptions of effective features of educational podcasts. West J Emerg Med. 2020, 22:26-32. 10.5811/westjem.2020.10.49135

15. Salvucci DD, Taatgen NA: Threaded cognition: an integrated theory of concurrent multitasking. Psychol Rev. 2008, 115:101-30. 10.1037/0033-295X.115.1.101

16. Gottlieb M, Riddell J, Cooney R, King A, Fung CC, Sherbino J: Maximizing the morning commute: a randomized trial assessing the effect of driving on podcast knowledge acquisition and retention [IN PRESS] Ann Emerg Med. 2021, 10.1016/j.annemergmed.2021.02.030

17. Chang YK, Labban JD, Gapin JI, Etnier JL: The effects of acute exercise on cognitive performance: a metaanalysis. Brain Res. 2012, 1453:87-101. 10.1016/j.brainres.2012.02.068

18. Pastore R, Ritzhaupt AD: Using time-compression to make multimedia learning more efficient current research and practice. TechTrends. 2015, 59:66-74. 10.1007/s11528-015-0841-2

19. Craik FI, Govoni R, Naveh-Benjamin M, Anderson ND: The effects of divided attention on encoding and retrieval processes in human memory. J Exp Psychol Gen. 1996, 125:159-80. 10.1037/0096-3445.125.2.159

20. Phillips JL, Heneka N, Bhattarai P, Fraser C, Shaw T: Effectiveness of the spaced education pedagogy for clinicians' continuing professional development: a systematic review. Med Educ. 2019, 53:886-902. 10.1111/medu.13895 